\title{
Experimental Investigation of Small-Scale Magnetocaloric Refrigerator
}

\author{
J. KAŠTIL ${ }^{a, b, *}$, J. TĚTEK ${ }^{c}$ AND A. TUČEK ${ }^{c}$ \\ ${ }^{a}$ Charles University, Faculty of Mathematics and Physics, Department of Condensed Matter Physics \\ Ke Karlovu 5, 12116 Prague 2, Czech Republic \\ ${ }^{b}$ Institute of Physics ASCR, v.v.i, Na Slovance 2, 18221 Prague 8, Czech Republic \\ ${ }^{c}$ TechSoft Engineering, Na Pankráci 26, 14000 Prague 4, Czech Republic \\ (Received April 5, 2013; in final form August 6, 2013)
}

\begin{abstract}
The small-scale magnetocaloric cooling device was developed at Czech Technical University in Prague. The magnetocaloric small-scale cooling system was designed as push-pull system with two permanent magnets with field of about $0.85 \mathrm{~T}$. The construction offers a possibility to alter independently many parameters of the cooling process and it ensures easy way to change working material and design of heat exchangers. The measurements were performed with $35 \mathrm{~g}$ of gadolinium as a working material and ethanol as heat transfer liquid. Device was successfully operated at room temperature with maximal heat span of $3.1 \mathrm{~K}$. In the article we report design of the machine and first measurement performed on it.
\end{abstract}

DOI: 10.12693 /APhysPolA.124.740

PACS: $75.30 . \mathrm{Sg}, 75.50 . \mathrm{Ww}$

\section{Introduction}

Magnetocaloric refrigeration attracted great attention in recent years. It represents environmentally friendly and possibly more effective alternative to classical gas compression method. The magnetic refrigeration uses magnetocaloric effect (MCE) discovered by Warburg in 1880 's as a change of temperature of material by application of magnetic field. In 1930's this principle was proposed for obtaining temperatures below $1 \mathrm{~K}$ and a method of adiabatic demagnetization was introduced by Debye and Giauque. Discovery of materials which show MCE around room temperature [1-11] and everyday need of more efficient technology leads to an idea of constructing refrigeration machines operating on basis of magnetic cooling. Moreover, such machines can give the opportunity to exploit the waste heat [12] or by using several stages construction the gases can be liquefied. Even though several prototypes were introduced to scientific and industrial community a further investigation of optimal MCE material, heat exchangers, heat exchange media and many other aspects of the cooling process are needed to construct an optimally working device.

It is possible to choose between many magnetocaloric materials nowadays. One of best MCE materials are substituted $\mathrm{La}(\mathrm{Fe}, \mathrm{Si})_{13}[13-15]$ with entropy change reaching more than $30 \mathrm{~J} \mathrm{Kg}^{-1} \mathrm{~K}^{-1}, \mathrm{Gd}_{5}(\mathrm{Si}, \mathrm{Ge})_{4}[6,7], \mathrm{Ni}_{2} \mathrm{MnGa}$ [1] based compounds in which the giant MCE is connected to the existence of coupled magnetostructural transition. MnFePAs [9] is an example of material with first order magnetic transition and by proper composi-

*corresponding author; e-mail: jirka.kastil@gmail.com tion it is able to tune the transition temperature in significant temperature region. Disadvantage of these materials is relatively narrow temperature dependence of magnetocaloric quantities (entropy change $\Delta S$ and temperature change $\Delta T$ ) and their price. Number of reports in the literature about amorphous metallic rare-earth based material present interesting entropy change in very broad temperature region, although transition temperatures are usually far below $300 \mathrm{~K}$. We should also mention pure Gd which is a benchmark material and due to its mechanical properties it is also wildly used in prototypes of refrigerators.

Several testing machines were presented in the literature starting from simple apparatus for testing magnetocaloric materials to industrial prototypes in last few years [16-19]. Interesting design of solid state device was tested by Silva et al. [20]. The research and development of the magnetic cooling technology was also summarized in several review articles [21, 18]. The most effective and powerful devices are characterised by rotational design and they are using active magnetic regenerator (AMR) cooling cycle. One of the latest design was introduced by Engelbrecht et al. [22]. The device was able to reach 25 degrees temperature span and maximal power was $1010 \mathrm{~W}$. The $2.8 \mathrm{~kg}$ of $\mathrm{Gd}$ was used in regenerators. Machines with smaller amount of magnetocaloric materials were also reported. The amount of $0.11 \mathrm{~kg}$ of Gd was used by Tura and Rowe [23]. Their device was able to operate with $10 \mathrm{~K}$ temperature span with $50 \mathrm{~W}$ of cooling power. As the cost of rare earth is high, the small scale devices are very important as they do not need large quantity of magnetocaloric material nor of the permanent magnets.

Even though the presented prototypes are already very promising, the coefficient of performance is still small. The benefit of the magnetic refrigeration is reduction of 
substances harmful for environment in today prototypes. The efficiency of magnetic cooling can be and need to be further improved to fully utilize the potential of the technique. In this work we present highly variable small scale testing magnetic refrigerator which represents easy way to test and find optimal materials and conditions for building and operating real effective refrigeration device.

\section{Refrigerator design}

The device was designed as push-pull small-scale refrigerator. The construction allows us quickly and easily exchange between different working material and heat exchangers as well as control the operational parameters (frequency, transported amount of heat exchange media, etc.) without any mechanical adjustments. One of the most important parts of the refrigerator machine is the working material inserted in magnetic regenerators. By changing the composition of the working material we can play with the operation temperature, temperature span and cooling power. It is also possible to use the material in different forms and shapes in our setup. Different shape offers different contact area which results in different heat exchange with heat exchange media. It also leads to different pressure drop of the exchange media.

Measurements of these properties are very important for practical devices. We can modify speed of magnetization and demagnetization process which can give interesting information about influence of eddy current on the refrigerator efficiency. It is possible operate this device as AMR, where different parts of working material undergo cooling cycle at different temperatures, or simply make all working material operate at one temperature by adjusting an amount of the heat exchange media transported during one cooling cycle. Most importantly we are able to change all parameters independently which brings the possibility to investigate also completely different thermodynamic cycles e.g. Ericsson-like cycle or Brayton-like cycle. Number of thermocouples was used to record temperatures during the operation of the refrigerator. We recorded also temperature of the surrounding. All data were collected by Agilent 34970A measurement station in time step of less than $1 \mathrm{~s}$.

The refrigerator consists of three heat exchangers (two hot and one cold), two cavities for working magnetocaloric material with volume of about $6 \mathrm{~cm}^{3}$, a piston for transportation of heat exchange media and three programmable electric motors. Sketch of the machine is plotted in Fig. 1.

\subsection{Heat exchangers}

Hot exchangers (HEX) are made of thin tubes enclosed in metallic outer jacket with plugs for connecting the exchanger to thermostat. Heat exchange media go through the tubes when the outer jacket can be kept at stable temperature. In the case of measurements described below we left the thermostat unplugged and the hot exchangers were cooled only by surrounding air.

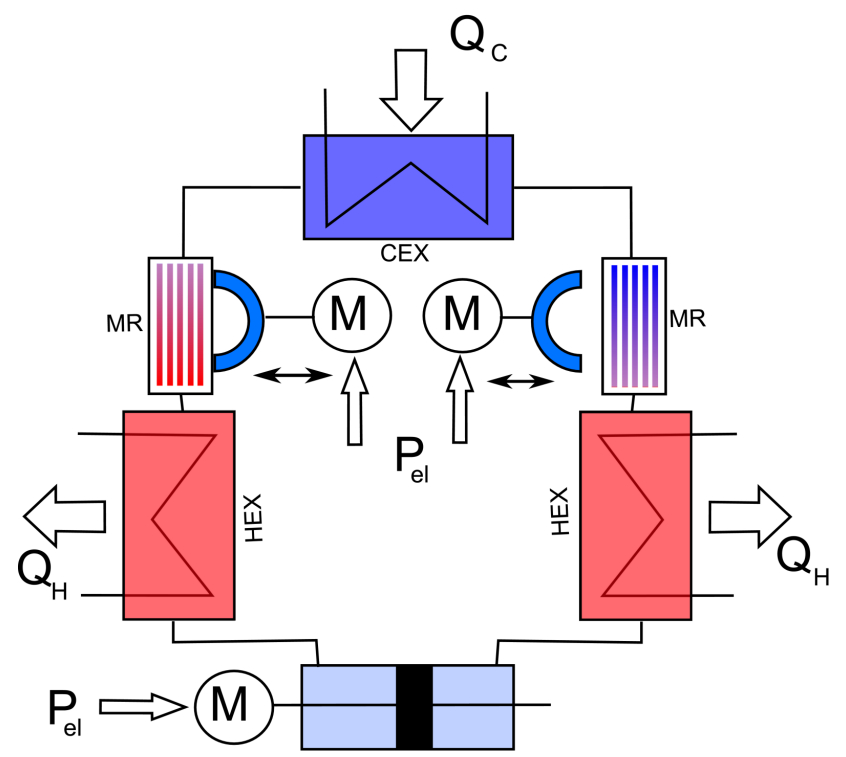

Fig. 1. Sketch of the machine built at CTU. $Q_{\mathrm{C}}$ is heat load, $Q_{\mathrm{H}}$ is heat emitted to surrounding, M represents electric motors, $P_{\mathrm{el}}$ is electric input, HEX are hot heat exchangers, CEX is cold heat exchanger and MR are magnetic regenerators.

Cold exchanger (CEX) was built from polypropylene tube isolated with commercial pipe insulation. Thermocouples were installed in heat exchanger to measure temperature of CEX ( $\left.T_{\text {Cold }}\right)$ during operation. The copper heater was inserted into cold exchanger for fluent change of heat load. This measurement shows very important dependence of the temperature span on the used heat load. When the heater is disconnected the heat load is given by heat absorbed by CEX from the surrounding.

\subsection{Magnetic regenerator}

Two rectangular shape cavities with volume of $6 \mathrm{~cm}^{3}$ can be filled with magnetocaloric material. We used $\mathrm{Gd}$ in form of thin foils with size of $0.15 \times 10 \times 60 \mathrm{~mm}^{3}$. A benefit of the foils is easy flow of the heat exchange media. Different result can be obtained with different orientations of the foil to the magnetic field [24] due to the demagnetization effects. Regenerators are placed symmetrically on each side of cold exchanger and closed by hot exchanger from the other side. The amount of $35 \mathrm{~g}$ of Gd metal is used in total. We measured temperature of both hot $\left(T_{\mathrm{H}}\right)$ and cold $\left(T_{\mathrm{C}}\right)$ side of the regenerator by thermocouples.

\subsection{Magnets}

$\mathrm{Nd}-\mathrm{Fe}-\mathrm{B}$ permanent magnets with iron yoke were used. The construction of each of them is little different (see Fig. 2). Maximal magnetic field is $0.95 \mathrm{~T}$ and $1.05 \mathrm{~T}$, respectively. The useful field change is about $0.85 \mathrm{~T}$ due to the stray field when magnets are far from regenerators. Spatial dependence of magnetic field was also calculated by software ANSYS Maxwell. 


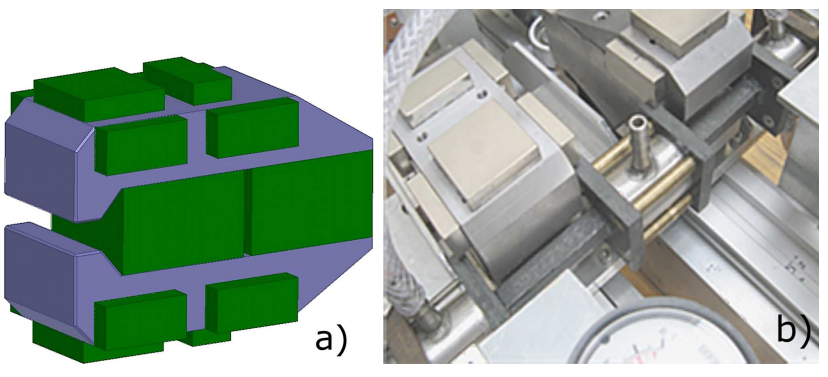

Fig. 2. Permanent magnet assembly used in refrigerator at CTU: (a) 3D model, (b) picture of mounted magnets.

\subsection{Motors and assembly}

Three programmable electric step motors ATAS G66UF308 drive magnets and piston. The parameters of the movement can be controlled and synchronized. All three motors are equipped by gearbox with ratio of 1:30. We can change acceleration and deceleration, velocity, angle of a turn, waiting time, and momentum. We can control amount and velocity of heat exchange media as well as time when the media is transported through the regenerators with respect to the magnet movement by changing the above parameters. The $3 \mathrm{D}$ view of the machine is given in Fig. 3 .

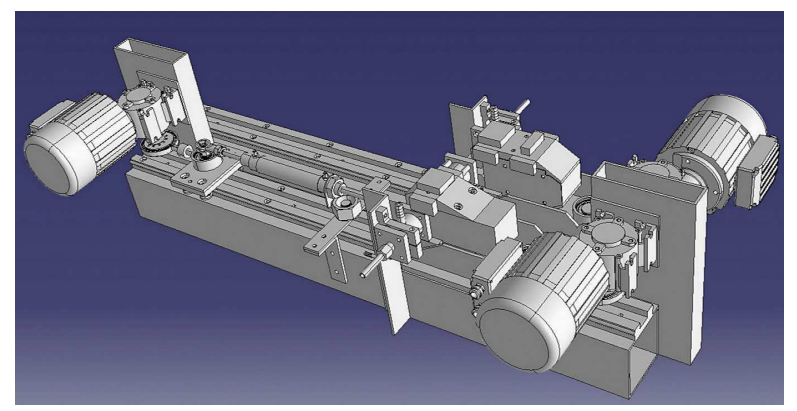

Fig. 3. 3D view of the machine built at CTU.

\section{Tests results and discussion}

Ethanol was used as heat exchange media and Gd $(35 \mathrm{~g})$ was used as a working material during the first measurements. Parameters changed in subsequent experiments were velocity of the magnet and piston movement (from 3 to $20 \mathrm{rpm}$ ) and lift of the piston - amount of heat exchange media $\left(6\right.$ and $\left.0.6 \mathrm{~cm}^{3}\right)$.

Time behaviour of temperature $T_{\mathrm{C}}$ is plotted in Fig. 4. These data were recorded at velocity of $9 \mathrm{rpm}$ and lift of the piston corresponding to $6 \mathrm{~cm}^{3}$. At first an increase of temperature can be seen due to a transfer of heat from ethanol to $\mathrm{Gd}$ bar which is moving to the CEX. Increase of $\mathrm{Gd}$ temperature continues as it is magnetized and shows magnetocaloric effect. Temperature decreases when ethanol moves to HEX and again decreases further due to magnetocaloric effect during demagnetization of Gd. Average temperature change of Gd caused by MCE is $1 \mathrm{~K}$ which is little bit less than values expected from literature for field change of $0.8 \mathrm{~T}$ and temperature around $292 \mathrm{~K}$ [25]. The reported values of adiabatic temperature change for $\mathrm{Gd}$ for field span of $0.85 \mathrm{~T}$ is about $2.7 \mathrm{~K}[25]$. This difference is mainly a result of non-adiabatic measurement in our case and some difference can be caused by different grade of Gd.

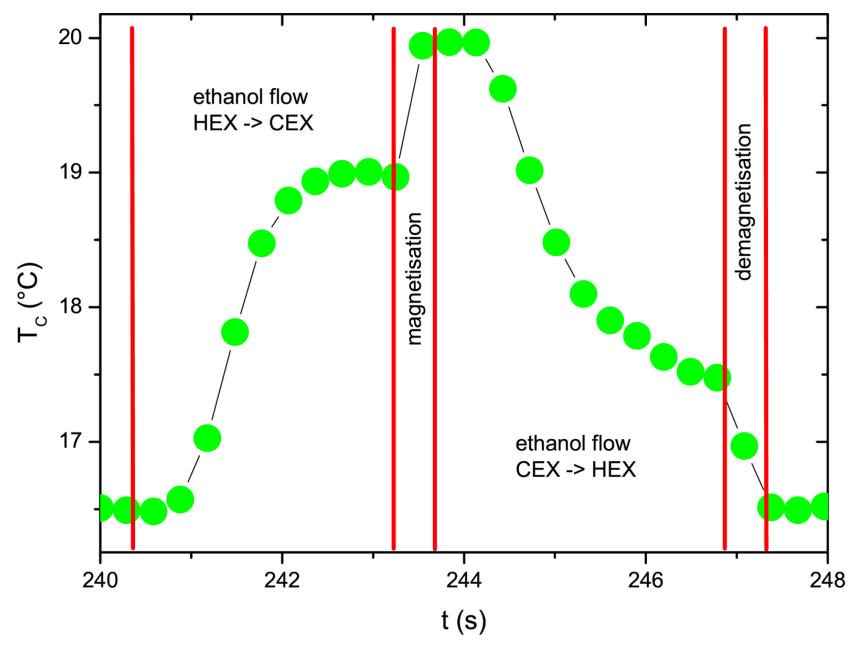

Fig. 4. Representative figure of time dependence of $T_{\mathrm{C}}$ during a cycle in stable state. Red lines mark different part of cooling cycle (ethanol flow in direction to CEX, magnetization of working material, ethanol flow in direction to HEX and magnetization of working material).

The time dependence of temperature $T_{\mathrm{H}}$ and $T_{\mathrm{C}}$ was recorded for all measurements. We plot this dependence as a floating average of $T_{\mathrm{H}}$ and $T_{\mathrm{C}}$ together with temperature of CEX $T_{\text {Cold }}$ in Fig. 5. Shown data were recorded for $12 \mathrm{rpm}$ and lift of the piston corresponding to $0.6 \mathrm{~cm}^{3}$. The maximum temperature span is $2.7 \mathrm{~K}$ and time from start to stability is approximately $400 \mathrm{~s}$. HEX were cooled only by surrounding air during the measurement. Results for all measured settings are given in Table.

TABLE

Results obtained for different settings of velocity and lift of the piston. Time to stability is time from start of the refrigerator to stable temperature span.

\begin{tabular}{c|c|c|c|c|c|c}
\hline \hline $\begin{array}{c}\text { Velocity } \\
{[\mathrm{rpm}]}\end{array}$ & $\begin{array}{c}\text { Lift } \\
{\left[\mathrm{cm}^{3}\right]}\end{array}$ & $\begin{array}{c}T_{\text {span }} \\
{[\mathrm{K}]}\end{array}$ & $\begin{array}{c}T_{\mathrm{H}} \\
{[\mathrm{K}]}\end{array}$ & $\begin{array}{c}T_{\mathrm{C}} \\
{[\mathrm{K}]}\end{array}$ & $\begin{array}{c}\text { Frequency } \\
{[\mathrm{Hz}]}\end{array}$ & $\begin{array}{c}\text { Time to } \\
\text { stability [s] }\end{array}$ \\
\hline 3 & 6 & 1.1 & 18.8 & 17.7 & 0.05 & 150 \\
6 & 6 & 1.5 & 18.8 & 17.3 & 0.10 & 185 \\
9 & 6 & 1.5 & 18.9 & 17.4 & 0.14 & 150 \\
20 & 6 & 1.2 & 18.2 & 17 & 0.28 & 45 \\
6 & 0.6 & 2.6 & 19.4 & 16.8 & 0.56 & 200 \\
12 & 0.6 & 3.1 & 20 & 16.9 & 0.83 & 300 \\
20 & 0.6 & 2.6 & 19.6 & 17 & 1.11 & 200
\end{tabular}

Measured data confirmed dependence of the $T_{\text {span }}$ both on the velocity as well as on lift of the piston. Velocity 


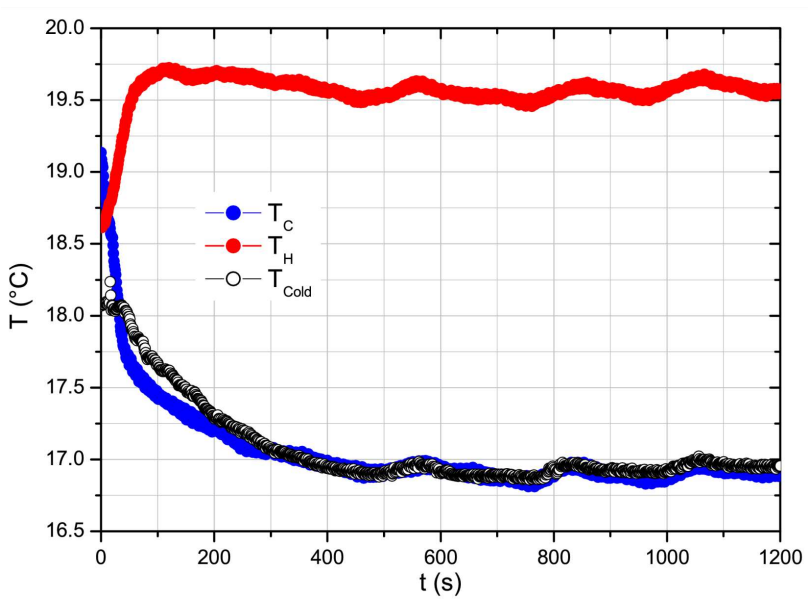

Fig. 5. Data recorded during the operation of the refrigerator with velocity of $12 \mathrm{rpm}$ and lift of the piston corresponding to $0.6 \mathrm{~cm}^{3}$.

dependence is determined mainly by transfer of the heat from working material to the heat exchange media e.g. thermal diffusivity of the system $\alpha$. Temperature relaxation of the Gd foils during one demagnetization process can be described by simple model

$$
T(t)=T_{0}+\Delta T \exp (-\alpha t),
$$

where $t$ is time, $T_{0}$ is a starting temperature and $\Delta T$ is temperature change of the Gd. Thermal diffusivity is dependent on the heat capacity of $\mathrm{Gd}$ as well as of heat exchange media and also on amount of the heat exchange media in contact with the $\mathrm{Gd}$ which is the reason of the velocity dependence of measured quantities. Temperature span was significantly enhanced by a change of lift of the piston which corresponds to a transport of different amount of heat exchange media.

Magnetic regenerators behave as AMR when the lift is decreased. The change from $6 \mathrm{~cm}^{3}$ to $0.6 \mathrm{~cm}^{3}$ leads to $50 \%$ increase of $T_{\text {span }}$. The decrease of the lift of the piston also reduces time needed for heat exchange media transport and this makes possible to reach higher operating frequencies. From temperature relaxation and known properties of the cold heat exchanger we roughly estimated thermal losses. The value of $\alpha$ was obtained by fitting the relaxation with Eq. (1). We approximated the CEX by $6 \mathrm{~cm}^{3}$ of ethanol. The amount of heat absorbed by CEX in one second was then calculated and the thermal losses were estimated to be $10 \mathrm{~W}$ for $2 \mathrm{~K}$ difference between surrounding and CEX.

\section{Conclusions}

We presented design of testing magnetic refrigerator built at CTU. The reciprocating system based on permanent magnets presents quick way how to change operating parameters and also working material can be easily replaced. Experimental values of magnetic field of assembled magnets were completed by numerical calculation in
ANSYS Maxwell. Numerical calculation of heat transfer in magnetic regenerators was performed in ANSYS Fluent R13 and ANSYS Structural. We can conclude that the machine can be operated around room temperature and used for measurement purposes. The maximal temperature span was measured to be $3.1 \mathrm{~K}$ and the estimated cooling power is $10 \mathrm{~W}$ for operating frequency of $0.83 \mathrm{~Hz}$ and $0.6 \mathrm{~cm}^{3}$ of ethanol transferred during one cycle. These results are low for practical use however for $35 \mathrm{~g}$ of commercial grade $\mathrm{Gd}$ as a working material and magnetic field of about $0.85 \mathrm{~T}$ are rather satisfying. The first basic measurement was performed and recorded to check the suitability of the measurement setup. Further experiments can be performed to study different aspect of the refrigerator. The presented work demonstrated the functionality and high variability of the machine and foreshadowed a large variety of future experiments.

\section{Acknowledgments}

The work was started by Prof. Ota in 2008 in scope of a grant project GA 101/07/1173 at Czech Technical University in Prague (CTU) in cooperation with Prof. Sechovský from Charles University in Prague. The prototype of small-scale refrigerator was completely designed by Prof. Ota. Unfortunately he died before the device was prepared for its testing. We would like to deeply thank Prof. Ota for his hard work and his guidance. His ideas inspired our research.

\section{References}

[1] A. Aliev, A. Batdalov, S. Bosko, V. Buchelnikov, I. Dikshtein, V. Khovailo, V. Koledov, R. Levitin, V. Shavrov, T. Takagi, J. Magn. Magn. Mater. 272 , 2040 (2004).

[2] R. Bjork, C.R.H. Bahl, M. Katter, J. Magn. Magn. Mater. 322, 3882 (2010).

[3] E. Bruck, O. Tegus, D.T.C. Thanh, N.T. Trung, K.H.J. Buschow, Int. J. Refriger.-Rev. Int. Froid 31, 763 (2008).

[4] E. Bruck, O. Tegus, L. Zhang, X.W. Li, F.R. de Boer, K.H.J. Buschow, J. Alloys Comp. 383, 32 (2004).

[5] S. Jun, Q.Y. Dong, Y.X. Li, J.R. Sun, J. Alloys Comp. 458, 115 (2008).

[6] A.O. Pecharsky, K.A. Gschneidner, V.K. Pecharsky, J. Magn. Magn. Mater. 267, 60 (2003).

[7] V.K. Pecharsky, K.A. Gschneidner, J. Magn. Magn. Mater. 167, L179 (1997).

[8] D. Songlin, O. Tegus, E. Bruck, J.C.P. Klaasse, F.R. de Boer, K.H.J. Buschow, J. Alloys Comp. 334, 249 (2002).

[9] O. Tegus, E. Bruck, X.W. Li, L. Zhang, W. Dagula, F.R. de Boer, K.H.J. Buschow, J. Magn. Magn. Mater. 272, 2389 (2004).

[10] P.J. von Ranke, N.A. de Oliveira, S. Gama, Phys. Lett. A 320, 302 (2004).

[11] Y.X. Zhang, Z.G. Liu, H.H. Zhang, X.N. Xu, Mater. Lett. 45, 91 (2000). 
[12] D. Vuarnoz, A. Kitanovski, C. Gonin, Y. Borgeaud, M. Delessert, M. Meinen, P.W. Egolf, Appl. En. 100, 229 (2012).

[13] E.Z. Valiev, I.F. Berger, V.I. Voronin, V.A. Kazantsev, Crystallogr. Rep. 56, 1160 (2011).

[14] L. Jia, J.R. Sun, J. Shen, Q.Y. Dong, J.D. Zou, B. Gao, T.Y. Zhao, H.W. Zhang, F.X. Hu, B.G. Shen, J. Appl. Phys. 105, 07A924 (2009).

[15] M. Katter, V. Zellmann, G.W. Reppel, K. Uestuener, IEEE Trans. Magn. 44, 3044 (2008).

[16] T. Kawanami, S. Hirano, M. Ikegawa, K. Fumoto, J. Heat Transfer-Trans. ASME 133, 060903 (2011).

[17] M. Balli, O. Sari, C. Mahmed, C. Besson, P. Bonhote, D. Duc, J. Forchelet, Appl. En. 98, 556 (2012).

[18] K.A. Gschneidner Jr., V.K. Pecharsky, Int. J. Refriger. 31, 945 (2008).

[19] B.F. Yu, Q. Gao, B. Zhang, X.Z. Meng, Z. Chen, Int. J. Refriger. 26, 622 (2003).
[20] D.J. Silva, B.D. Bordalo, A.M. Pereira, J. Ventura, J.P. Araujo, Appl. En. 93, 570 (2012).

[21] B.F. Yu, M. Liu, P.W. Egolf, A. Kitanovski, Int. J. Refriger.-Rev. Int. Froid 33, 1029 (2010).

[22] K. Engelbrecht, D. Eriksen, C.R.H. Bahl, R. Bjork, J. Geyti, J.A. Lozano, K.K. Nielsen, F. Saxild, A. Smith, N. Pryds, Int. J. Refriger.-Rev. Int. Froid 35, 1498 (2012).

[23] A. Tura, A. Rowe, Int. J. Refriger.-Rev. Int. Froid 34, 628 (2011).

[24] J. Kastil, P. Javorsky, J. Kamarad, E. Santava, Appl. Phys. A-Mater. Sci. Proc. 104, 205 (2011).

[25] Y.I. Spichkin, A.V. Derkach, A.M. Tishin, M.D. Kuz'min, A.S. Chernyshov, K.A. Gschneidner, V.K. Pecharsky, J. Magn. Magn. Mater. 316 , E555 (2007). 